\title{
Suboccipital Concentric Craniotomy as Variant for Posterior Cranial Fossa Surgery
}

\author{
Abraham Ibarra-de la Torre', Fernando Rueda-Franco ${ }^{2}$ \\ and Alfonso Marhx-Bracho ${ }^{2}$ \\ ${ }^{1}$ Hospital Central Sur de Alta Especialidad, PEMEX and \\ 2Instituto Nacional de Pediatría \\ Mexico
}

\section{Introduction}

In the early development of neurosurgery, a common procedure was the posterior cranial fossa surgery exposition using craniectomy.

The approaches to the posterior fossa were directed largely via the occipital squama; with figure of some authors that proposed suboccipital craniectomy and/or craniotomy. The suboccipital concentric craniotomy it's a variant for posterior cranial fossa surgery which considers the principle of fronto-orbital approach, use the concentric craniotomy technique by Laligam N Sekhar, Fotios N Tzortzidis and Jair L Raso in 1997.

\section{Alternative procedures}

As told, in the early development of neurosurgery, the posterior cranial fossa surgery exposition using craniectomy and/or craniotomy was a common procedure and several authors had described this approach, including combined approaches. Including midline suboccipital craniotomy, superior or inferior, for lesions such tumors of the culmen, pineal tumors, medulloblastoma, cerebelar hemisphere astrocytoma, ependimoma of the IV ventricle, foramen magnum tumors, respectively. The lateral suboccipital craniotomy or paramedian and the lateral suboccipital retrosigmoid approach opening is placed entirely within the squamous portion (immediately inferior to transverse sinus and posteromedial to jugular bulb) out in a retromastoid fashion, the access it offers to the lateral surface of the cerebellar hemisphere is excellent. It is the flap that permits one to work effectively in the pontocerebelllar angle, the jugular foramen, or along the lateral surface of the medulla oblongata and pons. Neurinomas, meningiomas, epidermoids, dermoids, chordomas, chondromas, metastases, and cysts constitute the majority of tumors in this region. These techniques had risk of iatrogenic injury to venous sinuses and causing profuse venous bleeding or air emboli. We recently described the suboccipital concentric craniotomy as a variant for posterior cranial fossa surgery, as a variant that have advantage for minor risk of injuries on the venous sinuses, in midline or lateral suboccipital approaches. This paper is dedicated for the latest technique. 


\section{Indications and contraindications}

Injuries of the posterior fossa are varied and different neurosurgical diseases. The indications in this case series were medulloblastoma 5 cases, midline suboccipital craniotomy; pineal germinoma 4 cases, using midline (superior) suboccipital craniotomy; pilocytic atrocytoma in 2 cases, one midline suboccipital craniotomy and the other lateral suboccipital craniotomy; each one case for arteriovenous malformation and aneurysm associated, cerebellar metastases, neurinoma, trigeminal neuralgia. We consider that the suboccipital concentric craniotomy may be used in the different neurosurgical lesions in the posterior fossa, including cerebellar, pineal and the pontocerebellar angle tumors, cerebellar metastasis, vascular lesions and vascular decompression in cranial nerves. This technique has application in children and/or adults. Without contraindications in these cases. Maybe using this craniotomy with combined approach for petroclival meningiomas, suprainfratentorial pre-sigmoid sinus avenue, such previous reports for Al-Mefty et al. and Samii and Ammirati, in 1988 or Miller et al, in 1993.

\section{Preoperative planning}

\subsection{Imaging}

Computed tomography (CT) or magnetic resonance Imaging (MRI) can establish the diagnosis (alone or together) of the posterior fossa lesion.

\subsection{Preoperative preparation}

Most of the patients diagnosed with a posterior fossa lesion can be stabilized by using steroids, this given 8 to 48 hours before tumor resection in hopes of reducing peritumoral edema and lowering ICP administer a histamine blockers as prophylactic are at the clinican's discretion; and cerebrospinal fluid diversion, for treat the hydrocephalus using external ventricular drain (EVD) or shunt insertion; the EVD inserted just before the craniotomy, during the same anesthetic; postoperatively, remove bloody, debris-laden cerebrospinal fluid and avoid the risk of acute postoperative hydrocephalus.

\subsection{Position}

The anesthetized patient is placed in the sitting position (the prone position, the venous oozing obscured the operative field), and the Mayfield three-point fixation device is used to fix the head and the neck slightly flexed forward, for midline approach and a midline linear skin incision (6-7 centimeters in lenght) begins $2-3 \mathrm{~cm}$ above the level of the external occipital protuberance and extends as far as $\mathrm{C}_{2-3}$. Dissection of the underlying soft tissue is completed. For the lateral suboccipital approach the skin incision begins approximately $3 \mathrm{~cm}$ above and slightly lateral to the external occipital protuberance and extends linearly down 6-8 $\mathrm{cm}$ toward the base of the occiput, but may vary. The transesophageal echography was use only in the cases of pineal tumors.

The position and size of major dural sinus were identified for using neuroimaging (see Fig. 2-J). In the midline superior suboccipital craniotomy, lesions such pineal tumor, we don't open the foramen magnum. 


\subsection{Anatomic landmarks in the posterior cranial fossa}

The orientation for any neurosurgical approach begins with consideration of surface anatomic landmarks; the relationships of surface structures to the internal anatomy, and the proper placement of the bony opening (strategic or initial burr-hole). The transverse and sigmoid sinuses are the natural limits of these exposures, the knowledge of the cranial topography constitutes the main factor in the planning of these posterior approaches and reliable landmarks would therefore guide the surgeon in order to reduce the risk of iatrogenic injuries.

The inion and superior nuchal line, the sagittal, lamboid, occipitomastoid, and parietomastoid sutures are recognizable structures on the external cranial surface and their relationships with the transverse and sigmoid sinuses and torcular herophili or superior sagittal sinus; the asterion, the junction of the lamboid, parietomastoid, and occipitomastoid sutures, has been used in posterior fossa surgery to locate the transverse-sigmoid sinus transition complex.
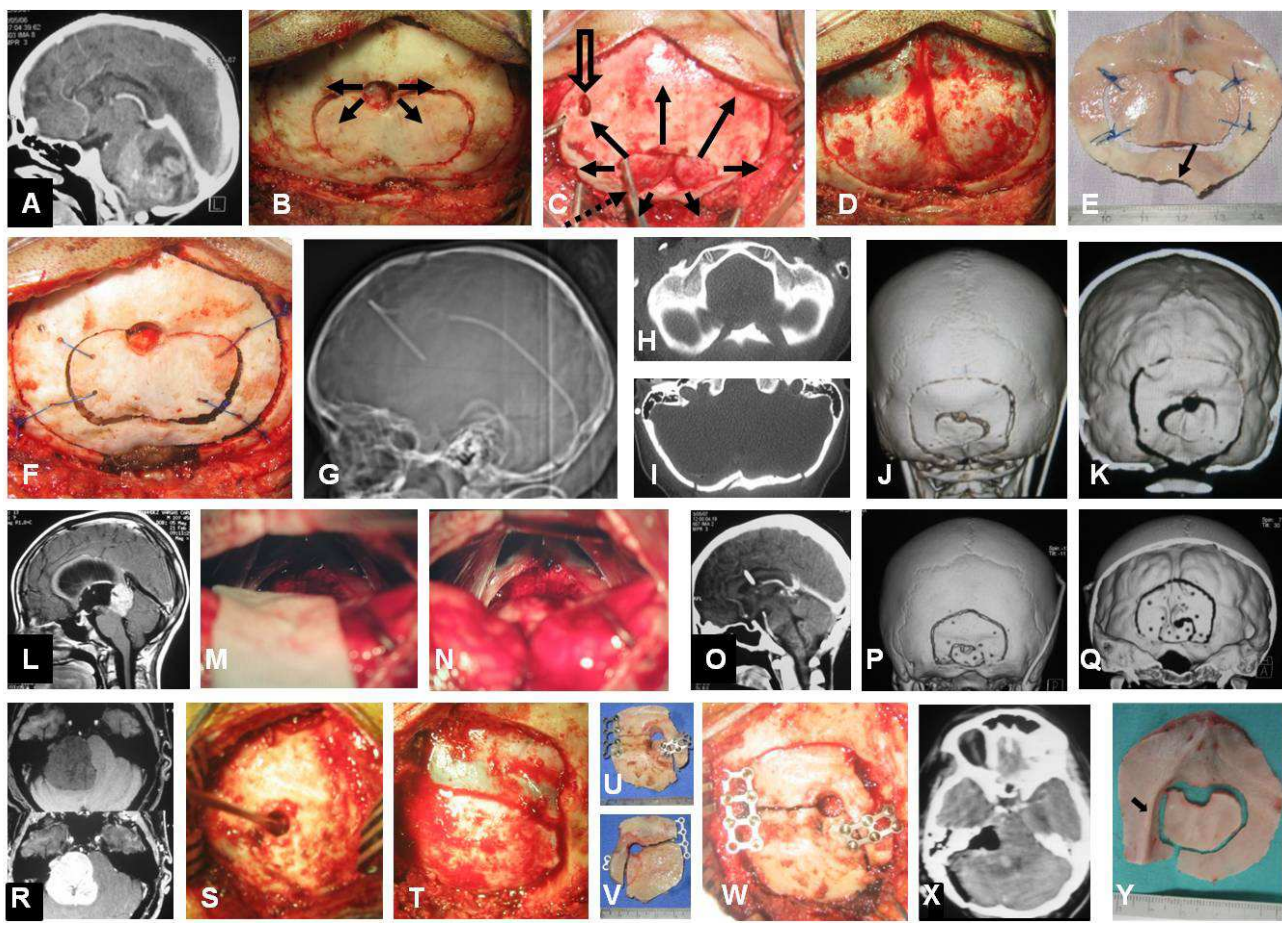

Fig. 1. Surgical technique. Cases $3(A, B, D$ to $G), 11(C), 6(H$ to $K), 10$ ( $L$ to $Q), 16$ ( $R$ to $X)$ and $4(Y)$; the patient with a medulloblastoma by cranial computed tomography $(C T)$ (A) suboccipital concentric craniotomy, medial approach, initial burr-hole inferior to inion and epidural dissection (arrows) for initial craniotomy (B), follow with new epidural-venous sinus dissection (black arrows), look the venous sinus separating (open arrow) with use of dissector through the initial craniotomy (dotted arrow) $(C)$, and cut the complete craniotomy $(D)$ without venous sinus injury; internal cranial view of bone flap with foramen magnum opening (arrow) $(E)$, fixed the bone flap $(\boldsymbol{F})$, in neuroimaging using CT with reconstruction 
suboccipital, $(G)$, foramen magnum $(H)$, occipital squama $(I)$, tridimensional reconstruction $(J, K)$. Suboccipital concentric craniotomy, medial approach, the patient with germinal tumor in pineal region, neuroimaging using magnetic resonance imaging (MRI) T1 weighted with gadolinium $(\boldsymbol{L})$, infratentorial-supracerebellar approach with the tentorium in situ $(\boldsymbol{M})$ and after retraction gentile $(N)$; CT in the post-surgical $(O)$ and tridimensional reconstruction without foramen magnum opening $(\boldsymbol{P}, Q)$. Suboccipital concentric craniotomy, lateral approach, the patient with right pontocerebellar angle neurinoma in MRI T-1 weighted simple and with gadolinium $(\boldsymbol{R})$, and in the surgical approach the initial burr-hole inferior and medial to the asterion, dissector in the epidural level $(S)$ and exposure de venous sinus transverse sinus (TS) with junction to sigmoid sinus (SS) and right infra- and supratentorial dura mater $(T)$, the bone flap with two craniotomies fixed to the cranium $(U-W), C T$ postsurgical; and a case with bone "keel-like" projection intracranially, arrow (Y).

\section{Key steps of the procedure}

\subsection{Surgical technique}

Patient place in prone and/or sitting position, the Mayfield three-point fixation device is used to fix the head. Midline or lateral linear incision and dissection of the underlying soft tissue is completed. The bone flap of concentric craniotomy, using high velocity drill, in midline or lateral suboccipital craniotomy; initial burr hole inferior to inion, $1 \mathrm{~cm}$ inferior and medial to asterion, for midline and lateral approach, respectively; and epidural dissection of internal occipital through the burr hole, cut a small-initial bone flap, after this, it's necessary to make an epidural-venous sinuses dissection from internal occipital trying separating it, cut de bone flap for a complete approach requiring with preservation of venous sinuses. Dural open and microsurgical approach is made. Close dural and the two bone flap are fixed; follow with close standard form in the level muscular and skin (Fig. 1).

\section{Postoperative care}

For the first days after posterior fossa craniotomy, we must attend postoperative pain; intravenous morphine is the standard for analgesia in the intensive care unit. Synthetic opioids such as fentanyl are also available. Ketorolac and other nonsteroidal antiinflammatory agent would avoid these probably for fear of their antiplatelet effects and increased risk of bleeding. Corticosteroids are given in constant doses in the postoperative, primarily dexamethasone (1-10 $\mathrm{mg} \mathrm{q} 6 \mathrm{~h})$, are frequently used postoperatively in neurosurgical patients. Complications of delayed wound healing, gastric ulceration, and infection should be monitored; as well as histamine blockers (ranitidine 50mg IV q8h, famotidine 20mg IV q12h) or proton pump inhibitor is reasonable in the immediate postoperative period. Patients receiving prolonged steroid therapy could considered for continued ulcer prophylaxis. Antibiotic prophylaxis for neurosurgical conditions has various antibiotic regimens such gentamicin with vancomycin, cefalozin, piperacillin, or oxacillin, first-generation cephalosporin for minor risk of infection.

We can use external ventricular derivation or shunt in which symptoms of hydrocephalus occur.

Risks of operation include wound infection, ventriculitis/meningitis, cerebrospinal fluid leak, cerebellar signs or the posterior fossa syndrome of mutism or death. 
Postoperative scans to determine whether residual lesion and suboccipital anatomical reconstruction.

\section{Complications}

Using the suboccipital concentric craniotomy in these cases, we none had injuries and/or tear of venous sinuses, in the posterior cranial fossa surgery.

\section{Outcome}

We reviewed 17 consecutive patients, who underwent surgical resection for posterior cranial fossa lesions at the Departments of Neurosurgery, in the Hospital Central Sur de Alta Especialidad, PEMEX and the InstitutoNacional de Pediatría, from Mexico City, between March 2005 to February 2008. The charts with the clinical data (age, sex, preoperative symptoms and signs), pre- and postoperative imaging studies, and operative notes (extent of resection, surgical technique) were analyzed.

The seventeen patients who were treated with suboccipital concentric craniotomy and were reported previously, show important data: age from 2 to 64 years old, media 17.23; 9 were male and female 8; 14 children and 3 adults (Table 1 ).

The diagnosis of the neurosurgical lesions in the posterior fossa were 15 tumors (6 medulloblastomas, 4 pineal tumors, 3 pilocytic astrocytoma, 1 neurinoma, 1 metastasis.), 1 vascular lesion and 1 trigeminal neuralgia.

Additional data: the suboccipital concentric craniotomy shows the surface in the craniotomy measures in children for medial approach was of $37.3 \mathrm{~cm}^{2}$ (range $22.5 \mathrm{~cm}^{2}$ to $47.5 \mathrm{~cm}^{2}$ ) and lateral approach $15.5 \mathrm{~cm}^{2}$ (range $14.0 \mathrm{~cm}^{2}$ to $17.1 \mathrm{~cm}^{2}$ ) and in the adults, for medial approach $32.5 \mathrm{~cm}^{2}$ and lateral approach $15.37 \mathrm{~cm}^{2}$ (range $10.5 \mathrm{~cm}^{2}$ to $\left.20.25 \mathrm{~cm}^{2}\right)$.

In these cases, we don't have complications for neurosurgical procedure.

\section{Expert suggestions}

The suboccipital concentric craniotomies for posterior cranial fossa surgery, in the midline and/or lateral, permit access to several infratentorial lesions and with risk reduced for injuries to venous sinuses and avoid profuse bleeding and/or air embolism; useful the external landmarks for initial burr hole and follow the craniotomy.

Too necessary technical aspect, such in the 4 case, that presented a bone "keel-like" projection intracranially (see Fig. 1,Y). With the principle of suboccipital concentric craniotomy, for preservation of dural and/or venous sinuses, too have applications in other cases for incomplete resection as cerebellar abscess and edema (performed a previously craniectomy), for cerebellar hemangioblastoma and edema and/or for sagittal synostectomy in sagittal craniosynostosis (in a patient with multiple synostosis)(Fig. 2).

\section{Explicative cases}

Case 6. This 6 year old girl was admitted with headache, vomiting, asthenia, with early symptomatic management for gastrointestinal disease without improvement for one month. 


\begin{tabular}{|c|c|c|c|c|c|c|c|c|c|c|c|}
\hline \multirow[t]{4}{*}{ Case } & \multirow{4}{*}{$\begin{array}{l}\text { Gender } \\
(\delta / \mathcal{I}) \\
\text { age } \\
\text { (years) }\end{array}$} & \multirow[t]{4}{*}{ Clinical manifestations } & \multirow[t]{4}{*}{ Image } & \multirow[t]{4}{*}{ Diagnostics } & \multicolumn{6}{|c|}{ Suboccipital concentric craniotomy } & \multirow{4}{*}{$\begin{array}{l}\text { Compli- } \\
\text { cations. }\end{array}$} \\
\hline & & & & & \multicolumn{4}{|c|}{ Measure (cm) } & \multicolumn{2}{|c|}{ Surface $\left(\mathrm{cm}^{2}\right)$} & \\
\hline & & & & & \multicolumn{2}{|c|}{ Middle } & \multicolumn{2}{|c|}{ Lateral } & & & \\
\hline & & & & & Initial & Complete. & Initial & Complete & Initial & Complete & \\
\hline 1 & 98 & $\mathrm{ICH}, \mathrm{CerSx}$. & $C T$ & $\begin{array}{l}\text { Medulloblastoma, } \\
\text { HCF, }\end{array}$ & $3.0 \times 3.5$ & $4.5 \times 6.0$ & No. & No. & 10.5 & 27.0 & No. \\
\hline 2 & 99 & ICH. & $\mathrm{CT}, \mathrm{MRI}$ & $\begin{array}{l}\text { Medulloblastoma, } \\
\text { HCF. }\end{array}$ & $2.5 \times 3.0$ & $4.5 \times 5.5$ & No. & No & 7.5 & 24.7 & No. \\
\hline 3 & 85 & $\mathrm{ICH}, \mathrm{CesSx}$. & $C I$ & $\begin{array}{l}\text { Medulloblastoma, } \\
\text { HCF. }\end{array}$ & $2.2 \times 3.5$ & $3.2 \times 6.2$ & No. & No. & 7.7 & 32.2 & No. \\
\hline 4 & 815 & ICH, ParinaudSx. & $\mathrm{CT}, \mathrm{MRI}$ & $\begin{array}{l}\text { Pineal germinoma } \\
\text { "HCF }\end{array}$ & $2.0 \times 2.5$ & $5.0 \times 6.0$ & No & No & 5.0 & 30.0 & No. \\
\hline $5 \ddagger$ & 99 & ICH, CerSx. & $C I, M R I$ & Medulloblastoma & No. & No. & $1.2 \times 2.3$ & $3.5 \times 4.0$ & 4.2 & 14.0 & No. \\
\hline 6 & 96 & $\mathrm{ICH}$. & $\mathrm{CT}, \mathrm{MRI}$ & $\begin{array}{l}\text { Medulloblastoma, } \\
\mathrm{HCF} \text {. }\end{array}$ & $2.5 \times 3.0$ & $6.6 \times 7.2$ & No. & No. & 7.5 & 47.5 & No. \\
\hline 7 & 34 & Cephalea. & $\mathrm{CT}, \mathrm{MRI}$ & $\begin{array}{l}\text { AVM and aneurysm } \\
\text { associate. }\end{array}$ & $2.0 \times 3.2$ & $4.6 \times 5.8$ & No. & No. & 6.4 & 26.7 & No. \\
\hline 8 & 86 & $\mathrm{ICH}, \mathrm{CerSx}$. & $\mathrm{CT}, \mathrm{MRI}$ & Medulloblstoma, $\mathrm{HCF}$. & $1.4 \times 2.0$ & $4.9 \times 5.4$ & No. & No. & 2.8 & 26.5 & No. \\
\hline 9 & 813 & ICH, ParinaudSx. & $\mathrm{CT}, \mathrm{MRI}$ & $\begin{array}{l}\text { Pineal germinoma, } \\
\mathrm{HCF}\end{array}$ & $1.8 \times 2.8$ & $4.5 \times 5.0$ & No. & No. & 5.0 & 22.5 & No. \\
\hline 10 & 310 & ICH, ParinaudSx. & $\mathrm{CT}, \mathrm{MRI}$ & $\begin{array}{l}\text { Pineal germinoma, } \\
\mathrm{HCF}\end{array}$ & $1.7 \times 2.6$ & $4.7 \times 5.8$ & No. & No, & 4.4 & 27.3 & No. \\
\hline 11 & 97 & ICH, CerSx. & $\mathrm{CI}, \mathrm{MRI}$ & Pilocytic astrocytoma. & $1.9 \times 3.5$ & $6.1 \times 7.4$ & No. & No. & 6.6 & 45.1 & No. \\
\hline 12 & 82 & ICH, CerSx. & $\mathrm{CI}, \mathrm{MRI}$ & $\begin{array}{l}\text { Pilocytic astrocytoma, } \\
\text { HCF. }\end{array}$ & $1.8 \times 3.3$ & $5.5 \times 6.5$ & No. & No. & 5.9 & 35.7 & No. \\
\hline 13 & 810 & ICH, ParinaudSx. & MRI & Pineal germinoma,HCF & $2.0 \times 3.2$ & $5.0 \times 5.5$ & No. & No. & 6.4 & 27.5 & No. \\
\hline 14 & 87 & ICH, CerSx. & MRI & Pilacytic astrocytoma. 1 & No. & No. & $2.0 \times 2.4$ & $3.5 \times 4.9$ & 4.8 & 17.1 & No. \\
\hline 15 & $\cong 59$ & ICH, CerSx, & $\mathrm{CT}, \mathrm{MRI}$ & Cerebellarmetastasis & $4.0 \times 3.0$ & $6.5 \times 5.4$ & No. & No- & 12.0 & 32.5 & No. \\
\hline 16 & $\cong 59$ & $\mathrm{ICH}, \mathrm{CerSx}$. & $\mathrm{CT}, \mathrm{MRI}$ & Neurinoma & No. & No. & $3.5 \times 3.0$ & $4.5 \times 4.5$ & 10.5 & 20.25 & No. \\
\hline 17 & $\cong 64$ & Facialpain. & MIRI & Trigeminal neuralgia & No. & No. & $2.5 \times 3.0$ & $3.0 \times 3.5$ & 7.0 & 10.5 & No. \\
\hline
\end{tabular}

Table 1. Present the consecutive cases and results for use the suboccipital concentric craniotomy. 

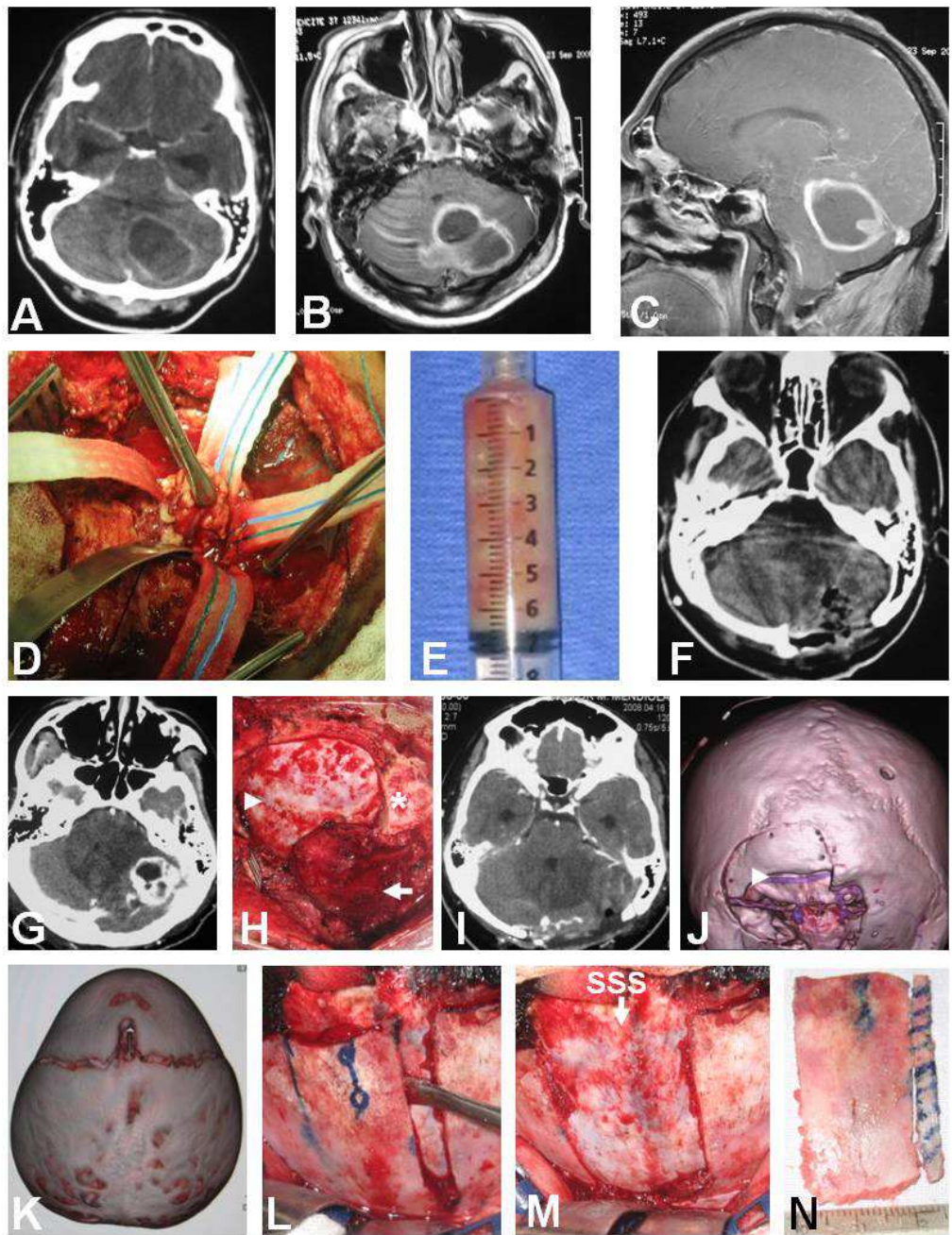

Fig. 2. Other applications with the principle of concentric craniotomy for preservation dural and/or venous sinuses. Such as a case of diabetic patient without take her hypoglycemic treatment, with cerebellar abscess and edema, posterior to drainage for sterotactic approach two weeks early, imaging CT and MRI, annular lesion and mass effect $(\boldsymbol{A}, \boldsymbol{B}, \boldsymbol{C})$, intraoperative capsular resection $(\boldsymbol{D})$, the pus $(\boldsymbol{E}), \mathrm{CT}$ post/operative $(\boldsymbol{F})$, in this patient performed shunt previously and craniectomy; too another case had before craniectomy and derivation ventricular external for hydrocephalus and hemangioblastoma $(G)$, that performed re-operation see the cerebellum with congestion and herniated (arrow), preservation dural and transverse sinus (arrowhead) in the left side $(\boldsymbol{H})$ total resection of tumor (I), duraplasty, concentric craniotomy and left transverse sinus (arrow) by CT tridimensional $(J)$; and other patient with craniosynostosis for oxicephaly $(K)$, with dissection dural and sagital superior sinus (SSS)with early craniotomy parasagital longitudinal $(\boldsymbol{L})$, preservation of SSS $(\boldsymbol{M})$ and sagittal synostectomy $(\mathrm{N}) .{ }^{*}$ Inion. 
Neurological examination revealed papilledema, horizontal nystagmus towards the left, incoordination and left brachial hypotonic (maneuver`s Stewart-Holmes positive). Imaging, in the CT and MRI with obstructive hydrocephalus and tumor in the posterior fossa in the medline probably rising on the cerebellar vermis and quadrigeminal cistern extensions. First was we installed a shunt, with improvement. The operation performed with the patient in the sitting position, midline incision and suboccipital "concentric" craniotomy, without dural tear and/or venous sinuses injuries, following tumor resection (see Fig. 1, $H$ to $K$ ). Postoperative course, the patient with improvement and had anatomical suboccipital reconstruction.

Case 17.A 52 year old female with headache, staggering gait with vertigo for one month and lowering of the hearing. Neurological examination revealed papilledema, incoordination and adiadochokinesia on the right side. Imaging, TC and MRI, showed obstructive hydrocephaly and a vestibular schwannoma in the right cerebellopontine angle. Was need performed a shunt and the operation (see Fig. $1, R$ to $X$ ), with total resection for lateral suboccipital craniotomy using the "concentric" form, without dural and/or venous sinuses injury exposed. Postoperative course, the patient had right facial paralysis and hypoesthesia V1, V2; with anatomical suboccipital reconstruction.

\section{Acknowledgments}

To David Alejandro Díaz Méndez, M.C., and Gloria Angélica Díaz Méndez, M. D., Doria Díaz Ibarra, by preparing this manuscript.

\section{References}

A proposal for more informative abstracts of clinical articles.Ad Hoc Working Group for Critical Appraisal of the Medical Literature.Ann Intern Med 1987; 106:598-604.

Abolghassem S, Ulrich K. Osteoplastic lateral suboccipitalapproach for acoustic neuroma surgery, technical note.Neurosurgery 2000;48:229-231.

Al-Mefty O, Fox JL, Smith RR. Petrosal approach for petroclivalmeningiomas. Neurosurgery 1988; 22:510-517.

Avci E, Kocaogullar Y, Fossett D, Caputy A. Lateral posteriorfossa venous sinus relationships to surface landmarks. Surg Neurol 2003; 59: 392-7.

Bozbuga M, Boran BO, Sahinoglu K. Surface anatomy of theposterolateral cranium regarding the localization of the initialburr-hole for a retrosigmoid approach. Neurosurg Rev 2006;29:61-63.

Bucy PC. Exposure of the posterior or cerebellar fossa.J Neurosurg1966; 24: 820-832.

Critchley M.: Discussion on the differential diagnosis of lesions of the posterior fossa. Proc $R$ Soc Med 1953; 46:719-738.

Dandy WE.The treatment of trigeminal neuralgia by the cerebellar route.Ann Surg1932; 96:787-795.

Day JD, Kellogg JX, Tschabitscher M, Fukushima T. Surfaceand superficial surgical anatomy of the posterolateral cranialbase, significance for surgical planning and approach. Neurosurgery 1996; 38: 1079-1084.

Day JD, Tschabitscher M. Anatomic position of the asterion. Neurosurgery 1998; 42: 198-199. 
Gharabaghi A, Rosahi SK, Feigl GC, Liebig T, Mirzayan JM, Heckl S, Tatagiba M, Samii M. Image guided lateral suboccipital approach: part 1individualized landmarks for surgical planning. Neurosurgery 2008; 62:S18-S23.

Haynes RB, Murlow CD, Huth EJ, Altman DG, Gardner MJ. More informative abstracts revisited. Ann Intern Med 1990; 113:69-76.

Ibarra A, Aguilar R. Craneotomía suboccipital concéntrica como variante en cirugía de fosa posterior: nota técnica. Arch Neurocien (Mex), 2009; 14:206-210.

Ibarra A, Marhx A, Rueda F, Mora I. Craneotomía suboccipital concéntrica para cirugía craneal infratentorial: resultados quirúrgicos en una serie de 14 casos. Arch Neurocien (Mex), 2009; 14:151-156.

Ibarra A, Marhx A, Rueda F. Suboccipital concentric craniotomy as variant for posterior cranial fossa surgery: outcome in a case series (paper 90). Presented at the 38th Annual Meeting of the International Society for Pediatric Neurosurgery, Jeju, South Korea, October 31 to November 4, 2010. Childs Nerv Syst 2010; 26: 1435-1476.

Jannetta PJ. Hemifacial spasm.In: Samii M, Jannetta PJ (editors), The cranial nerves, anatomy, pathology, pathophysiology, diagnosis, and treatment. Springer-Verlag, Berlin, 1981.

Jannetta PJ. Vascular decompression in trigeminal neuralgia. In: Samii M, Jannetta PJ (editors), The cranial nerves, anatomy, pathology, pathophysiology, diagnosis, and treatment. Springer-Verlag, Berlin, 1981.

Kempe LG. Operative neurosurgery, posterior fossa, spinal cord, and peripheral nerve disease. Springer-Verlag, New York, 1970.

Lang J Jr, Samii A. Retrosigmoid approach to the posterior cranial fossa, an anatomical study. Acta Neurochir (Wien) 1991; 111: 147-153.

Lang J Jr, Samii A. Retrosigmoid approach to the posteriorcranial fossa, an anatomical study. Acta Neurochir (Wien) 1991;111:147-153.

Levy ML, Apuzzo ML.: Supracerebellarinfratentorial approaches to the pineal region. In: Rengachary SS, Wilkins RH (editors), Neurosurgical operative atlas. Vol. 4, Park Ridge, Illinois, American Association of Neurological Surgeons, 1995, pp. 29-36.

Marlin AE, Gaskill SJ.Cerebellar medulloblastoma.In:Rengachary SS, Wilkins RH (editors), Neurosurgical operative atlas.Vol. 1, Williams and Wilkins, Baltimore, American Association of Neurological Surgeons 1991, pp 176-83.

Miller CG, van Loveren HR, Keller JT, Pensak M, El-Kalliny M,Tew JM Jr. Transpetrosal approach: surgical anatomy andtechnique. Neurosurgery 1993; 33:461-469.

Ogilvy CS, Ojemann RG. Posterior fossa craniotomy for lesionsof the cerebellopontine angle.J Neurosurg1993; 78: 508-9. 19.

Page LK. The infratentorial-supracerebellar exposure of tumors in the pineal area. Neurosurgery 1977; 1: 36-40.

Poppen JL. An atlas of neurosurgical techniques.WB. Saunders, Philadelphia, 1960.

Raimondi AJ. Pediatric neurosurgery, theoretical principles artof surgical techniques. SpringerVerlag, New York. 1987.

Rhoton AL Jr. The posterior cranial fossa, microsurgical anatomy and surgical approaches.Neurosurgery 2000; 47:S5-S6.

Ribas GC, Rhoton AL Jr, Cruz OR, Peace D. Suboccipital burrholes and craniectomies. Neurosurg Focus 2005; 19: 1-12. 
Samadiana M, Nazparvar B, Haddadian K, Rezaei O, Kormaee F. The anatomical relation between the superior sagittal sinus and the sagittal suture with surgical considerations. Clin Neurol Neurosurg 2011;113:89-91.

Samii M, Ammirati M. The combined supra-infratentorialpresigmoidsinus avenue to the petro-clival region.Surgicaltechnique and clinical applications. Acta Neurochir (Wien) 1988;95:6-12.

Sekhar LN, Tzortzidis F, Raso J. Fronto-orbital approach. In: Sekhar LN, De Oliveira E (editors), Cranial microsurgery, approaches and techniques, Thieme, New York, 1997: 54-60.

Stein BM. The infratentorialsupracerebellar approach to pineal lesions. J Neurosurg1971; 35: 197-202.

Stein BM. The infratentorial-supracerebellar exposure of tumors in the pineal area. Neurosurgery 1977; 1: 36-40.(Comment).

Tew JM, van Loveren HR. Atlas of operative microneurosurgery.W. B. Saunders Company, Philadelphia, 1994.

Tubbs RS, Loukas M, Shoja MM, Bellew MP, Cohen-Gadol AA. Surface landmarks for junction between the transverse and sigmoid sinuses: application of the "strategic" burr hole for suboccipital craniotomy. Neurosurgery 2009; 65:S37-S41.

Tubbs RS, Salter G, Elton S, Grabb PA, Oakes WJ. Sagittal suture as an external landmark for the superior sagittal sinus. J Neurosurg 2001; 94:985-987.

Tubbs RS, Salter G, Oakes WJ.Superficial surgical landmarksfor the transverse sinus and torcularherophili. J Neurosurg 2000; 93: 279-281.

Yasargil MG, Fox JL. The microsurgical approach to acousticneurinomas.SurgNeurol1974; 2: 393-8.

Yasargil MG. Microneurosurgery. Georg ThiemeVerlag,Stuttgart, 1984; (1):238-244.

Yasargil MG. Microneurosurgery.IVB, Georg ThiemeVerlag,Stuttgart, 1996. 
EXPUCATIVE CASES OF

CONTROVERSIAL

ISSUES IN

NEUROSURGERY

tdiced by francescos simorell

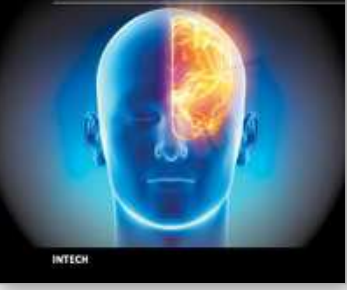

\section{Explicative Cases of Controversial Issues in Neurosurgery}

Edited by Dr. Francesco Signorelli

ISBN 978-953-51-0623-4

Hard cover, 534 pages

Publisher InTech

Published online 23, May, 2012

Published in print edition May, 2012

Neurosurgery is a rapidly developing field of medicine. Therefore, staying keeping track of the advancements in the field is paramount for trainees as well as fully trained neurosurgeons. This book, fully available online, is a part of our effort of improving availability of medical information for anyone who needs to keep up-to-date.

\section{How to reference}

In order to correctly reference this scholarly work, feel free to copy and paste the following:

Abraham Ibarra-de la Torre, Fernando Rueda-Franco and Alfonso Marhx-Bracho (2012). Suboccipital Concentric Craniotomy as Variant for Posterior Cranial Fossa Surgery, Explicative Cases of Controversial Issues in Neurosurgery, Dr. Francesco Signorelli (Ed.), ISBN: 978-953-51-0623-4, InTech, Available from: http://www.intechopen.com/books/explicative-cases-of-controversial-issues-in-neurosurgery/suboccipitalconcentric-craniotomy-as-variant-for-posterior-cranial-surgery

\section{INTECH}

open science | open minds

\section{InTech Europe}

University Campus STeP Ri

Slavka Krautzeka 83/A

51000 Rijeka, Croatia

Phone: +385 (51) 770447

Fax: +385 (51) 686166

www.intechopen.com

\section{InTech China}

Unit 405, Office Block, Hotel Equatorial Shanghai

No.65, Yan An Road (West), Shanghai, 200040, China

中国上海市延安西路65号上海国际贵都大饭店办公楼 405 单元

Phone: +86-21-62489820

Fax: +86-21-62489821 
(C) 2012 The Author(s). Licensee IntechOpen. This is an open access article distributed under the terms of the Creative Commons Attribution 3.0 License, which permits unrestricted use, distribution, and reproduction in any medium, provided the original work is properly cited. 